\title{
A NEGATIVIDADE DA POÉTICA DE JOÃO CABRAL: PROPOSTA DE ESTUDO
}

THE NEGATIVITY OF JOÃO CABRAL'S POETICS: A STUDY PROPOSAL

Felipe Oliveira de Paula*

RESUMO: No primeiro momento, situo a discussão entre os críticos cabralinos sobre a noção de negatividade. Alio a esse breve apontamento de parte da fortuna crítica do poeta o conceito de negatividade desenvolvido por Theodor Adorno ao longo de seus trabalhos, concentrado em Dialética Negativa. Em seguida, procuro demonstrar qual e como se estabelece uma chave interpretativa para analisar a poesia de Cabral. A negatividade, tal como trabalhada, se apresenta como ferramenta promissora para investigar como o questionamento da linguagem na poética cabralina reflete os elementos técnicos literarios e, a um sót poética crítica a dispositivos sociais, sobretu(a) do quando esses não aparecem explicitamente.

PALAVRAS-CHAVE: Poética; João Cabral; Negatividade.
* fopaula@yahoo.com.br

Doutor em Estudos Literários pela Universidade Federal de Minas Gerais. Mestre pela mesma instituição e licenciado em Letras Português e Literaturas de Lingua Portuguesa, pela Universidade ederal de Viçosa.

ABSTRACT: In the first moment, I situate the discussion among the cabralino critics about the notion of negativity. I add to this brief note on part of the poet's critical fortune the concept of negativity developed by Theodor Adorno throughout his works, but concentrated on Negative Dialectics (1966). Next, I try to demonstrate what and how an interpretative key is established to analyze Cabral's poetry. Negativity, as worked, presents itself as a promising tool to investigate how the questioning of language in Cabral's poetics reflects the technical literary elements and at the same time, configures a critical poetics of social devices, especially when they do not appear explicitly.

KEYWORDS: Poetics; João Cabral; negativity. 
A poesia de João Cabral de Melo Neto tem uma fortuna crítica extensa, já foi analisada por várias perspectivas e não é novidade interpretar sua obra a partir de certa noção de negatividade. O termo por si só comporta diversas significações e pode remeter a diferentes caminhos para entender a poesia cabralina, como fizeram Benedito Nunes, João Alexandre Barbosa, Marta Peixoto e Antonio Carlos Secchin em algum momento de suas análises.

Benedito Nunes publica em 1971 o livro pioneiro sobre os estudos do poeta: Ioão Cabral de Melo Neto. Nele, o crítico afirma que a obra do poeta pernambucano se desenvolveu em uma crise interna, ou seja, em uma luta consigo mesma, e já em O Engenheiro (1945) sua poética submete o processo criador a uma análise reflexiva e crítica que viabiliza selecionar e julgar o resultado desse procedimento. $\mathrm{O}$ que o autoriza a interpretar, por conseguinte, sobre a própria crise histórica da poesia, problematizando, por meio de uma poética negativa, o alcance da lírica moderna. Pois bem, interessa, neste momento, o que Benedito Nunes considera "poética negativa", título de um dos capítulos de seu livro, no qual analisa Psicologia da Composição com a Fábula de Anfion e Antiode (1947).

João Cabral tentava no seu primeiro livro, conforme Benedito Nunes, abranger e fundir dois planos: o da linguagem e o da experiência psicológica. Mas quando em
Psicologia da composição o papel da "atenção" ganha maior foco em detrimento da "evocação da memória" (muito presente em Pedra do Sono - 1942), o poeta nega o segundo plano e visa direta mente o primeiro; "enquanto o outro, reduzido pela depuração que o impessoalizou, torna-se realidade dissipada e ausente, da qual o poema surge" (NUNES, 1974, p. 54). Nesse sentido, a poética de Cabral é caracterizada como negativa por realizar-se contra a "experiência psicológica", em sentido inverso a ela, e, principalmente, desfazendo o que ela impõe. Essa "luta consigo mesma", de que fala o crítico, faz o poeta compor seu poema ao se decompor. "Despindo algo de si, ele provoca o vazio que as palavras vêm preencher".

\section{Saio do meu poema}

Como quem lava as mãos

[..]

talvez, como a camisa

vazia, que despi.

\section{(MELO NETO, 1994, p. 93). ${ }^{1}$}

Benedito Nunes concebe o termo negativo no sentido de recusar criticamente algo que esteve presente em Pedra do
1. Todas as citações de obras ficcionais e ensaios do autor, salvo quando sinalizado, foram retiradas de Obra Completa, ediçãa organizada por Marly de Oliveira e publicada pela editora Nova Aguilar, 1994. Por isso, consta na bibliografia a indicação da Obra Completa.
EM TESE
BELO HORIZONTE
v. 25
N. 3
SET.-DEZ. 2019
PAULA. A negatividade da poética de João Cabral: proposta de estudo
P. 133-142 
2. João Alexandre Barbosa defende a tese de que não há como separar a poesia de Joáo Cabral em duas, como, por exemplo, "tipo lunar" e "tipo solar-concreto", como fez Luiz Costa Lima. Para ele, a poética cabralina pode ser percebida na relação entre composição e comunicação, mas que, em certos poemas, há o extremar de um o outro vetor.
Sono e, de modo geral, na tradição literária: a experiência pessoal. Contudo, essa recusa não se dá apenas por um não falar, mas em tornar o que se nega elemento constituidor de sua poesia ao substituir lembrança por atenção.

$\mathrm{Na}$ esteira do pensamento de Benedito Nunes, a tese de livre docência de João Alexandre Barbosa, $A$ imitação da forma (1975), apropria e aprofunda a discussão sobre poética negativa qua ndo a nalisa Psicologia da composição com a Fábula de Anfion e Antiode. Para o estudioso, é muito importante compreender o sentido dessa negatividade porque ela será o fundamento para se entender a transição do vetor composição para comunicação ${ }^{2}$ e o modo pelo qual o poeta articula significado e significação enquanto constrói o poema.

Isso justifica o espaço dedicado por João Alexandre para falar tanto do primeiro quanto do segundo termo da expressão "poética negativa". A negatividade é concebida

como uma recusa a partir da qual é possível repensar os dados da criação. Ao usar-se o termo "poética", como faz Benedito Nunes, introduz-se o componente decisivo de configuração: não se tra ta de uma resposta transitória, através da qual simplesmente fosse negada a poesia, mas a incorporação ao poema de uma recusa básica em vista da qual ele é problematizado. O que se recusa, portanto, é a perpetuidade de uma poética e, por isso, ela é negativa. (BARBOSA, 1975, p. 58).

O "tríptico da poética negativa de João Cabral”3 já demonstra essa recusa ao utilizar como epígrafe o verso riguroso horizonte, de Jorge Guillén. Como escla rece João Alexandre, o fato de usar o verso do poeta espanhol indica que os três poemas estão direcionados para construir, pela poesia, o espaço de clareza e equilíbrio através de certa linguagem que busca uma metáfora para o poema, "o seu poema possível” - perseguido nos textos da trilogia. João Cabral se mostra no rastro da poesia praticada por Jorge Guillén que é concebida como um espaço a ser construído e alcançável, recusando-se a esforçar por algo que esteja além dos limites do possível. Evidencia-se, com isso, sua resistência em se alinhar à concepção de poésie pure defendida por Paul Valéry, pois, como demonstra João Alexandre, Jorge Guillén vai contra essa ideia porque, para ele, só existe poesia enquanto feita num poema, e o que defende Valéry é um estado poético (BARBOSA, 1975, p. 60).

Marta Peixoto também trabalhou certa noção de negatividade na poesia cabralina em sua pesquisa de doutorado defendida em 1977 na Universidade de Princeton, depois adaptada e publicada como livro, Poesia com coisas (1983). No entanto, o sentido se aplica à construção semântica do
3. Como nomeou Benedito Nunes o livro Psicologia da composição com a Fábula de Anfion e Antiode. Para tanto, ver Benedito Nunes (1974, p. 46).
EM TESE
BELO HORIZONTE
v. 25
N. 3
SET.-DEZ. 2019
PAULA. A negatividade da poética de João Cabral: proposta de estudo
P. $133-142$ 
texto literário. Na análise do poema "Imagens em Castela", de Paisagens com Figuras (1956), a estudiosa demonstra como o poema vai configurando uma "imagem hiperbólica e cumulativa de vastidão e vazio. A preposição 'sem', repetida várias vezes, revela a ausência inesperada de algum elemento ou função" (PEIXOTO, 1983, 118). Ao acompanhar de perto o desenvolvimento desse poema, e de outros do livro, Marta Peixoto chega à conclusão de que em todos os textos de Paisagens com Figuras ocorre um processo semelhante por oferecerem uma série de "imagens concretas que exemplificam com persistência os mesmos conceitos negativos: o vazio, o sem, o escasso, o nada e considerações sobre a temática da morte" (PEIXOTO, 1983, p.118). $\mathrm{O}$ negativo se estabelece, portanto, na linguagem descritiva que utiliza "quase sempre" objetos concretos ao lado de modificadores diminutivos e artefatos sem seus acessórios costumeiros, como no caso do poema "Imagens em Castela" ao relacionar a imagem da paisagem de Castela à de mesa:

É uma paisagem em largura,

de qualquer lado infinita.

É uma mesa sem nada
Na casa sem pé-direito,

na mesa sem serventia.

\section{(MELO NETO, 1994, p. 149).}

Antonio Carlos Secchin utiliza uma expressão mais eficaz para explicar esse mesmo mecanismo que ocorre no poema "A palo seco", qual seja, "intensificar por subtração" (SECCHIN, 1985, p. 164). As "palavras negativas" são fundamentais ao estilo de João de Cabral por diferenciar "aquilo que é" daquilo que "não é" em certo objeto. A um só tempo, as palavras que carregam essa negatividade ("sem", "nada", "nenhum" etc.) nomeiam uma paisagem constituída por traços nega tivos. Paradoxalmente, são essas mesmas "palavras negativas" que exprimem "os únicos valores positivos que Cabral propõe” (PEIXOTO, 1983, p. 121).

Marta Peixoto publicou seu livro dois anos antes do que Antônio Secchin (1985), o que, talvez, permita dizer que, no sentido exposto acima, suas análises coincidem em reconhecer a construção da poesia cabralina a partir de "imagens por subtração" (SECCHIN, 1985, p. 52); embora não seja possível encontrar na obra do acadêmico qualquer referência ao estudo de Peixoto. Assim como João Alexandre Barbosa investigou e reconheceu questões levantadas por Benedito Nunes, o mesmo acontece com Secchin em relação 
tanto a Alexandre Barbosa quanto ao próprio Benedito Nunes.

Antonio Carlos Secchin aprofundou essa perspectiva ao abranger sua reflexão pensando a poesia de João Cabral a partir da ideia de "poesia do menos"; isto é, a constância das "palavras negativas", que, além de definir uma retórica, como defende Marta Peixoto, serve para limpar o signo linguístico, "sempre visto como portador de um transbordamento de significado" (SECCHIN, 1985, p. 11). A "poesia do menos" é caracterizada exatamente por esse processo que retira do signo o excesso. O poeta pernambucano se posiciona, dessa maneira, tanto na antiga ordem de significações do signo quanto na nova ordem em que ele o instala. Nesse ponto, Carlos Secchin vai dialogar com Benedito Nunes e Alexandre Barbosa, visto que a "poesia do menos" desconfia da linguagem que usa e, nessa indagação, estabelece-se um questiona mento histórico que rejeita um espaço "neutro onde as palavras emergiriam em pureza original" SECCHIN, 1985, p. 11). Como fica explícito no poema "Antiode (contra poesia dita profunda)" quando o poeta expõe a relação da poesia com uma imagem de flor:

Poesia, te escrevia:

flor! conhecendo

que és fezes. Fezes

\section{(MELO NETO, 1994, p. 52).}

Nestes três versos, o sujeito poético problematiza a associação de poesia a uma imagem de flor que remete, quase sempre, a uma beleza pronta, decorativa e agradável aos olhos. Contudo, num movimento aparentemente simples de perceber como se forma uma flor é possível esclarecer sua íntima ligação com "fezes", imagem oposta à da flor tal como utilizada muitas vezes na tradição poética.

$$
* * *
$$

Essas são as noções de negatividade utilizadas, de modo geral e com poucas variações, pela fortuna crítica de Cabral e foram aproveitadas ao longo da tese $A$ poética negativa de João Cabral de Melo Neto. Entretanto, além delas, serviu como apoio para o desenvolvimento do estudo o conceito de negatividade desenvolvido por Theodor Adorno ao longo de suas obras, concentrado em Dialética Negativa (1966).

Adorno discute, pelo menos desde Dialética do esclarecimento (1944), obra feita junto com Max Horkheimer, de que modo parte da sociedade se apropriou de novas tecnologias esvaziando seus potenciais transformadores e impediu, assim, grandes modificações sociais. Ele vai argumentar no 
livro de 1966 que os mecanismos alienadores abrangem ta mbém a maneira de utilizarmos a linguagem, mais especificamente os conceitos. Devido ao modo de produção e reprodução da vida social, "os conceitos funcionais foram reprimindo cada vez mais os conceitos substanciais", o refletir sobre como, por que e a eficiência de utilizarmos determinado conceito foram sendo minados por processos reais: com isso, a sociedade "transformou-se em contexto funcional total” (ADORNO, 2009. p. 63). Cria-se, assim, uma falsa objetividade que nos torna aparentemente mais práticos e nos livra do questiona mento.

Tendo isso em mente, e que já em Platão a "dialética" se instaurava por meio de um pensamento de negação para gerar algo positivo, Adorno procura subverter a tradição filosófica ao propor uma "dialética negativa" que esteja "liberta de tal natureza afirmativa, sem perder nada em determinação" (ADORNO, 2009. p. 7). Uma primeira questão a se notar é que a dialética proposta não pretende uma síntese no sentido hegeliano e, aliado a isso, é contra o movimento que busca dar sentido à coisa por meio de sua apreensão conceitual, já que "dialética" significa que a coisa não é idêntica a seu conceito. Este não pode esgotar o objeto e, ainda assim, é um meio eficaz de pensá-lo. Por isso, é preciso experimentar o conceito para testar seus limites, e não abandoná-lo ou utilizá-lo arbitra ria mente.
Testar não significa aqui o simples jogar com as palavras para ver qual melhor se adequa à matéria, mas é um tipo de reflexão que procura abarcar no conceito o conceitual e o não-conceitual. $O$ conceitual pressupõe o que é incorporado do momento dinâmico da história e o não-conceitual é ir além do conceitual. Assim, para o conceito, o que se torna urgente é o que ele não alcança, o que é eliminado pelo seu mecanismo de abstração, o que deixa de ser um mero exemplar do conceito. Adorno não está preocupado em apontar a diferença entre realidade e conceito em vista da realização futura deste, mas em expor a sua diferença entre coisa e conceito diante de sua identidade social aparente (GATTI, 2009, p. 264). Não se deve aceitar com facilidade o dado, o que está cristalizado na tradição, mas buscar um conhecimento que desconfia do que está pronto. Esse conhecimento não é apreendido apenas por meio da abstração, mas, sobretudo, na composição sobre o conhecimento e o conceito. Decorre que a dialética negativa é um exercício de raciocínio que avalia sua possibilidade à medida que é realizado (ADORNO, 2009. p. 124). O que procuramos demonstrar, também, da poética de João Cabral.

O poeta pernambucano, consciente da impossibilidade de identificar o objeto no conceito, ou na imagem experimenta suas potencialidades ao passo que configura 
seus dizeres no poema. Esse processo pressupõe uma não-identificação e se vale dos conceitos/imagens tanto para denunciar sua lógica de identidade como para iluminar o que escapa a esta lógica de nomeação. Algo feito à medida que a discussão técnica de como construir imagens, metáforas, símiles, por exemplo, é exposta e usada como ferramenta para testar os limites e as capacidades semânticas, imagéticas das palavras. Esse procedimento poético pode ser visto nos versos inicias de "Antiode" quando o poeta questiona um movimento histórico que cristaliza a associação da poesia a apenas uma característica de flor, descartando partes importantes de sua constituição.

Esse recurso metapoético busca acompanhar o movimento dinâmico das coisas e, ao mesmo tempo, permite uma abertura para o real, não se restringindo a notas referenciais dos problemas sociais, mas a partir das discussões sobre as maneiras de dizê-lo. Isto é, no processo de pensar o procedimento técnico apropriado, que não se limita a uma cristalização da linguagem, procura-se abarcar no conceito o não-conceitual.

O materialista dialético aprofunda o conceito por meio de uma estrutura de apresentação ensaística, a qual permite acompanhar as idas e vindas de seu raciocínio. Contudo, se, por um lado, esse método dialético de exposição lhe é mais eficaz, por outro, dificulta, muitas vezes, que faça mos citações diretas de seu livro. Dizendo com outras palavras, a contribuição de Adorno se deve muito mais pelo tipo de raciocínio que ele estabelece ao tentar, a partir do questiona mento do que é idêntico, abarcar o não-idêntico, do que pela utilização de seus aforismos.

Nesse sentido, aproveitamos as noções de negatividade utilizadas pelos estudiosos de João Cabral, mas privilegiamos o conceito desenvolvido por Adorno. Salvo enga no, tal pesquisa ainda não foi feita dentro da fortuna crítica do poeta. Além disso, essa perspectiva pôde auxiliar nossa leitura da poética cabralina, que, em linhas gerais, propôs interpretar, por uma via negativa, poemas tradicionalmente concebidos como metalinguísticos e a íntima ligação que eles têm com a realidade.

$* * *$

Como se sabe, ler a poesia de João Cabral a partir de sua construção é algo comum entre os estudiosos de sua obra. Quem primeiro o fez foi Antonio Candido em "Poesia ao Norte". Ao comentar Pedra do Sono, ele chama a atenção para a presença de imagens ligadas ao sono estruturadas por "uma vontade ordenadora" e conclui seu argumento da seguinte maneira: "O seu [de Cabral] cubismo de construção é sobrevoado por um senso surrealista da poesia" (CANDIDO, 1999, p. 11). 
4. Ver, entre outros, os textos "Evolução de formas: poesia concreta" (de Haroldo de Campos) "Arte concreta: objeto e objetivo" (de Décio Pignatari). Cf. CAMPOS; CAMPOS; PIGNATARI, 2006.

5. Essa discursão foi feita de maneira mais aprofundada por Thais Mitiko Taussig Thoshimitsu em sua tese de doutorado: $O$ rio, a cidade $e$ o poeta: impasse e contradições na poesia de João Cabral de Melo Neto, de 2009
Mais tarde, os Concretistas, sobretudo os paulistas, na tentativa de filiar João Cabral à formação da poesia concreta, propuseram uma leitura interessada de Psicologia da composição e $O$ engenheiro, destacando e ostentando o alto rigor formal, a lucidez e a valorização da construção como procedimentos da poesia. Intensificada principalmente pelos irmãos Campos e Décio Pignatari (2006), ${ }^{4}$ essa linha interpretativa foi muito importante para esclarecer o método de composição de Cabral, mas, ao mesmo tempo, promoveu um paradigma de leitura sobre a obra do pernambucano. O problema não se deve ao fato de eles terem criado um caminho para se interpretar a poesia cabralina, mas ao fato de a fortuna crítica considerar esse paradigma concreto, salvo em alguns casos, como único meio de aprofundar um estudo sobre João Cabral. Os Concretistas estavam imbuídos de um projeto maior que procurava, ademais, garantir a João Cabral, por extensão à literatura brasileira, um lugar na produção literária e intelectual mundial, relacionando-o, frequentemente, à poesia francesa.

Esse direcionamento de leitura da poesia cabralina estabelecido pelos concretistas pode ser mais bem desenvolvido, ${ }^{5}$ contudo, tal caminho nos desviaria de nosso objetivo atual. O que importa, aqui, é notar que essa perspectiva afetou diretamente a compreensão da obra cabralina daî em diante, pois, mesmo críticos mais experientes, como
Luiz Costa Lima e José Guilherme Merquior e, em um grau menos intenso, Benedito Nunes e João Alexandre Barbosa buscaram manter a ideia de influência de Stéphane Mallarmé e Paul Valéry para compreender a elaboração e continuidade da poesia cabralina. Aos poucos, entretanto, a leitura que visa identificar a obra do pernambucano à sua pesquisa formal com a linguagem e à linha poética distinta de uma tradição lírica luso-brasileira (vista como ultrapassada pelos concretistas) está sendo relativizada. Neste sentido, alguns autores modalizam tal leitura da poesia de Cabral ao fornecer novas ferramentas interpretativas. ${ }^{6}$

O conceito "negativo" forneceu ferramenta para interpretarmos alguns poemas concebidos tradicionalmente como metalinguísticos por uma perspectiva que não foi, até então, adotada para análise dessa poesia, a saber: propor uma leitura que valorize as construções técnicas do poema e, ao mesmo tempo, revele sua íntima relação com o Nordeste cabralino. Tal raciocínio problematiza, ademais, uma visão dicotômica sobre a obra de João Cabral, dividida pela ideia de uma poesia que privilegia questões sociais e a de outra que se volta para a própria feitura do poema. Além disso, defendendo que o livro Psicologia da Composição com a Fábula de Anfion propõe um programa poético de João Cabral, seguimos de perto um de seus preceitos, que é perceber a poesia às avessas; caso entenda mos que, nesta
6. Ver, entre outros, o livro Joáo Cabral de Melo Neto (MACHADO, 2016), ou os textos "Dizendo-se de viès,/ Disse-me sempre': poesia e memória em João Cabral de Melo Neto" (FIUZA, 2017) e "João Cabral e Clarice Lispector: sim contra sim" (SIOUEIRA, 2016)
EM TESE
BELO HORIZONTE
v. 25
N. 3
SET.-DEZ. 2019
PAULA. A negatividade da poética de João Cabral: proposta de estudo
P. $133-142$ 
situação, deserto pode ser visto como uma metáfora para poesia:

\section{Cultivar o deserto}

como um pomar às avessas

(MELO NETO, 1994, p. 96).

Após esclarecer o que denominamos como poética negativa, pensamos ser mais produtivo entender a construção da obra como desencadea mento de uma articulação entre diversos fatores - mediados, quase sempre, por intertextualidades artísticas -, entre eles, a quadra, uma visão de mundo que sobressai na década de 1930 e o diálogo crítico que o poeta estabelece com seus contemporâneos. Com isso, rebate-se a interpretação que considera João Cabral um "cometa" dentro da literatura brasileira, ao mesmo tempo em que se estreita uma conversa com a fortuna crítica do poeta.

O método composicional de João Cabral se realiza no momento em que sua linguagem retira da nomeação qualquer certeza de univocidade e, por isso, ele, ao criar imagens cortantes, agressivas, desconfortáveis, para dizer o nordestino pobre, estabelece certo tipo de questionamento da própria metáfora, da metonímia, do símile etc. Como bem observou Benedito Nunes, a própria clareza que direciona a poesia de João Cabral não é a do "realismo ingênuo", que pressupõe o encontro com o real antes de qualquer esforço de simbolização. "É o ideal de adequação do realismo reflexivo, consciente de que o máximo de clareza a nós acessível 'não está no começo da linguagem, como uma idade de ouro, e sim no extremo do seu esforço"' (NUNES, 1974, p. 162). Nesse tipo de busca pela clareza poética perpassa uma concepção de que o movimento das palavras vem do movimento das coisas.

\section{REFERÊNCIAS}

ADORNO, Theodor. Dialética negativa. Trad. Marco Antônio Casanova. Rio de Janeiro: Zahar, 2009.

BARBOSA, João Alexandre. A imitação da forma. São Paulo: Duas cidades, 1975

CAMPOS, Augusto; CAMPOS, Haroldo; PIGNATARI, Décio. Teoria da poesia concreta: textos críticos e manifestos 1950-1960. Cotia, São Paulo: Ateliê Editorial, 2006.

CAMPOS, Haroldo. "Evolução de formas: poesia concreta". In: CAMPOS, Augusto; CAMPOS, Haroldo; PIGNATARI, Décio

Teoria da poesia concreta: textos críticos e manifestos 1950 1960. Cotia, São Paulo: Ateliê Editorial, 2006, pp. 77-88. 
CANDIDO, Antonio. Poesia a norte. IN:

Remate de

Males. Campinas: Unicamp, 1999, pp. 09-13.

FIUZA, Solange. 'Dizendo-se de viés,/ Disse-me sempre' poesia e memória em João Cabral de Melo Neto". In:

RIBEIRO, Renata Rocha; FIUZA, Solange; MANUEL, Antonio (org.). Goiânia: Editora UFG, 2017.

GATTI, Luciano. Exercícios do pensamento: dialética negativa. Novos estudos - CEBRAP, São Paulo, n. 85, p. 261-270, 2009. Disponível: http://www.scielo.br Acesso: 23 de maio de 2018.

MELO NETO, João Cabral. Obra completa: volume único. Organização Marly de Oliveira. Rio de Janeiro: Nova Aguilar, 1994

NUNES, Benedito. João Cabral de Melo Neto. Rio de Janeiro: Vozes, 1974

PEIXOTO, Marta. Poesia com coisas (uma leitura de João Cabral de Melo Neto). São Paulo: Perspectiva, 1983

SECCHIN, Antonio Carlos. João Cabral: a poesia do menos São Paulo: Duas cidades; Brasília: INL, Fundação nacional Pró-memória, 1985
SIQUEIRA, J S. "João Cabral e Clarice Lispector: sim contra sim". In: TOPA, Francisco; YOKOZAWA, S. F. C.; SIQUEIRA

J. S. (Org.). Estudos de literatura brasileira em Portugal: travessias. Porto: CITCEM / Edições Afrontamento, 2016, v. 1, p. 77-87.

TOSHIMITSU, Thaís Mitiko Taussig. O rio a cidade e o poeta: impasses e contradições na poesia de João Cabral de Melo Neto. 2009. 226p. Tese (Doutorado em Teoria da

Literatura e Literatura Comparada), Universidade de São Paulo, São Paulo, 2009

Recebido em: 05-09-2019. Aceito em: 26-01-2020.

EM TESE

BELO HORIZONTE

v. 25

N. 3

SET.-DEZ. 2019

PAULA. A negatividade da poética de João Cabral: proposta de estudo

P. 133-142 